Article

\title{
Sodium Butyrate Reduces Colitogenic Immunoglobulin A-Coated Bacteria and Modifies the Composition of Microbiota in IL-10 Deficient Mice
}

\author{
Tenghui Zhang ${ }^{1,2,+}$, Chao Ding ${ }^{2,+}$, Mingli Zhao ${ }^{1}$, Xujie Dai ${ }^{2}$, Jianbo Yang ${ }^{2}$, $\mathrm{Yi} \mathrm{Li}^{2}$, Lili Gu ${ }^{2}$, \\ Yao Wei ${ }^{2}$, Jianfeng Gong ${ }^{1,2, *}$, Weiming $\mathrm{Zhu}^{2}$, Ning $\mathrm{Li}^{2}$ and Jieshou $\mathrm{Li}^{2}$ \\ 1 Department of General Surgery, Jinling Hospital Affiliated to Southern Medical University, No. 305 East \\ Zhongshan Rd., Nanjing 210002, China; tenghuiff@163.com (T.Z.); zhao_ming_li@163.com (M.Z.) \\ 2 Department of General Surgery, Jinling Hospital, Medical School of Nanjing University, Nanjing 210002, \\ China; dingchao19910521@126.com (C.D.); d670677094@163.com (X.D.); yang_jianbo@126.com (J.Y.); \\ liyi1860@126.com (Y.L.); drgulili@163.com (L.G.); dr_betty@126.com (Y.W.); dr_zhuweiming@126.com (W.Z.); \\ proflining@163.com (N.L.); lijieshou@163.com (J.L.) \\ * Correspondence: gongjianfeng@aliyun.com; Tel.: +86-139-5189-0970 \\ + These authors contributed equally to this work.
}

Received: 6 September 2016; Accepted: 8 November 2016; Published: 24 November 2016

\begin{abstract}
High levels of immunoglobulin A (IgA)-coated bacteria may have a role in driving inflammatory bowel disease (IBD). We therefore investigated the effect of sodium butyrate on microbiota in IBD prone interleukin (IL)-10 $10^{-/-}$mice. At 8 weeks of age, mice were allocated into three groups ( $n=4$ /group): normal (C57BL/6), IL-10 $10^{-/}$, and IL- $10^{-/-}$treated with sodium butyrate (100 mM). Severity of colitis, inflammatory cytokine and short-chain fatty acid (SCFA) concentration in proximal colon contents, the percentage of IgA-coated bacteria and microbiota composition by $16 \mathrm{~S}$ ribosomal RNA assessment of stool were measured after 4 weeks of treatment. Sodium butyrate ameliorated histological colitis and decreased levels of tumor necrosis factor (TNF)- $\alpha$ and IL- 6 in IL-10 $10^{-/-}$mice compared with those without treatment. At the phylum level, a reduction in Bacteroidetes and an increase in Firmicutes in IL-10-/- mice treated with sodium butyrate were observed. Additionally, Prevotellaceae species were reduced in IL-10 ${ }^{-/-}$mice treated with sodium butyrate as compared with those without treatment. The level of biodiversity was slightly increased and the amount of IgA-coated bacteria decreased in IL-10 $10^{-/-}$mice treated with sodium butyrate compared with those without treatment. Our results indicate that sodium butyrate protects against colitis, possibly through modifying the gut microbiota, enriching biodiversity and reducing the amount of colitogenic IgA-coated bacteria in IL-10 $10^{-/}$mice.
\end{abstract}

Keywords: sodium butyrate; immunoglobulin A-coated bacteria; microbiota composition; colitis; IL-10-/- mice

\section{Introduction}

Altered composition of the gastrointestinal tract microbiota has been widely recognized as playing a major role in the pathogenesis of inflammatory bowel disease (IBD) [1-3], although the etiology of IBD remains largely unknown. Many studies consistently report a change in biodiversity, such as a reduction of the Firmicutes phylum in Crohn's disease (CD) patients $[4,5]$ and an increase of Enterobacteriaceae in IBD patients and mouse models [6]. Moreover, studies have observed individuals with IBD had increased bacterial translocation $[7,8]$ which has been proposed to trigger immune activation and inflammation. Furthermore, it has been found that the colitogenic bacteria contributing to disease severity or exacerbation of inflammation in IBD might be identified by high levels of immunoglobulin A (IgA) coating [9]. Secretory IgA, the predominant antibody isotype produced at 
mucosal surfaces, can not only provide protection against infection by binding pathogens, but also protect against mucosal penetration by commensals [10,11]. However, drugs or molecules modulating IgA-coated bacteria in the intestinal microbiota have never been investigated.

Among the most important environmental factors impacting microbial composition is diet, which has been demonstrated to influence microbiome composition throughout mammalian evolution [12]. It has been reported that Western-style diets, which are low in fiber, decrease beneficial Firmicutes and increase mucosa-associated Proteobacteria compared with a high fiber diet [13]. Additionally, the anti-inflammatory efficacy of dietary fibers in a murine colitis model of IBD has been indicated in many studies [14-16]. The effect of dietary fibers or synbiotics on the prevention of bacterial translocation in either experimental mice or humans also has been reported. Short-chain fatty acids (SCFAs), particularly acetate, propionate, and butyrate, are the products of fermented soluble dietary fiber. Sodium butyrate plays a crucial role as a fuel source for intestinal epithelial cells [17] and exerts effects on both gut morphology and function [18]. SCFAs contribute to normal large bowel function and prevent pathology through their modification by commensal microbiota and their metabolism by colonocytes. Depletion of sodium butyrate-producing bacteria in IBD microbiota is clearly evidenced by a reduction in sodium butyrate-producing metabolic pathways $[19,20]$, as well as in concentrations of fecal sodium butyrate [21,22]. Moreover, one study found that sodium butyrate regulates the size and function of the colonic Treg pool and protects against colitis in a GPR43-dependent manner in mice [23]. These results suggest that sodium butyrate reduces colitis by modulating the function and composition of both gut microbiota and leukocytes in IBD.

Thus, we hypothesized that sodium butyrate could ameliorate colitis by modulating the colonic commensal microflora, especially levels of IgA-coated bacteria. The objective of this study was to evaluate whether sodium butyrate would reduce colitis severity through modulation of microbiota in the interleukin (IL)-10 $10^{-/-}$mouse model of experimental IBD.

\section{Materials and Methods}

\subsection{Animals}

Both IL-10 ${ }^{-/-}$and wild-type mice (8 weeks old) on a C57BL/ 6 background were obtained from the Jackson Laboratory (Bar Harbor, ME, USA). Mice were bred and maintained in specific pathogen-free conditions at the Model Animal Research Centre of Nanjing University (Nanjing, China). The experimental procedures were performed in accordance with the Guidelines for Animal Experiments at Jinling Hospital and were approved by the Ethics Committee at Jinling Hospital (2014NLY-112). The mice were maintained on a 12-h dark-light cycle and allowed free access to food and tap water under controlled temperatures.

\subsection{Drug Administration Protocol}

Mice were coded and randomized into three groups (4 per group): C57BL/ 6 mice (control, tap water), IL-10 group (IL-10-/- mice, tap water), and the IL-10 + sodium butyrate group (sodium butyrate (Sigma-Aldrich, Shanghai, China) (100 mM: $1.1 \mathrm{~g}$ sodium butyrate dissolved in $100 \mathrm{~mL}$ water) administered orally in drinking water, with water bottles changed every 5 days). An equal number of males and females were used in each group. The mice were anesthetized by intraperitoneal administration of ketamine $(0.3 \mathrm{~mL} / 100 \mathrm{~g}$ body weight $)$ and euthanized 4 weeks after treatment. All samples were immediately frozen and stored at $-80^{\circ} \mathrm{C}$ excepted for proximal colons for histology.

\subsection{Histology and Colitis Scores}

Proximal colons were excised and cleaned with Dulbecco's phosphate buffered saline prior to fixation in $4 \%$ paraformaldehyde and then processed by routine paraffin embedding, sectioning and hematoxylin and eosin staining. Colitis scores were determined by two independent pathologists who were blinded to the experimental parameters. Each proximal colon segment was scored from 0 to 
4 using well-established criteria [24]. The summation of scores per mouse provided a total colonic disease score.

\subsection{Measurement of SCFAs}

Samples of proximal colon content were collected immediately after the animals were euthanized and stored at $-80^{\circ} \mathrm{C}$. The measurement of SCFAs was performed as described previously [25].

\subsection{Quantitative Real-Time RT-PCR}

Quantitative real-time PCR was performed with proximal colon as described previously [26] with primers specific for tumor necrosis factor (TNF)- $\alpha$ and IL-6. Relative expression was calculated using the $2^{-\Delta \Delta \mathrm{Ct}}$ method after normalizing to the housekeeping gene glyceraldehyde phosphate dehydrogenase (GAPDH). The sequences of the primers used were: TNF- $\alpha$ : $5^{\prime}$-CCTCTCTC TAATCAGCCCTCTG-3' , 5'-GAGGACCTGGGAGTAGATGAG-3'; IL-6: 5' -ACTCACCTCTTCAGAA

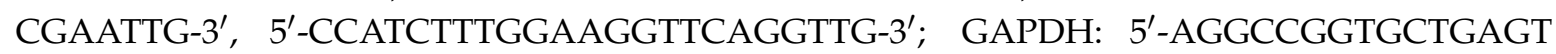
ATGTC-3', 5'-TGCCTGCTTCACCACCTTCT-3'.

\subsection{Fecal IgA-Coated Bacteria Flow Cytometry}

For detection of IgA-coated bacteria, we used a previously reported method [9]. Briefly, Fast Prep Lysing Matrix D tubes containing ceramic beads (MP Biomedicals, Santa Ana, CA, USA) were used for homogenization and PE-conjugated anti-mouse IgA (clone mA-6E1, 1:12.5 dilution; eBioscience, San Diego, CA, USA) was used for staining prior to flow cytometric analysis (Epics Altra, Beckman Coulter, Indianapolis, IN, USA).

\subsection{High Throughput Sequencing of Microbiota Using $16 S$ rRNA PCR}

Bacterial DNA was extracted and 16S rRNA gene amplicons were generated and sequenced on an Illumina MiSeq (Illumina Inc., San Diego, CA, USA) with MiSeq Control Software v. 2.2.0 (Illumina Inc., San Diego, CA, USA). Sequence data were processed and analyzed using QIIME. PCR amplification of the V5-V4 regions of the bacterial 16S $r R N A$ gene was performed using universal primers (515F 5'-GTGCCAGCMGCCGCGGTAA-3' and 907R 5'-CCGTCAATTCMTTTRAGT-3') incorporating a unique sample barcode sequences. For amplicon library preparation, $20 \mathrm{ng}$ of each genomic DNA, 1.25 U Taq DNA polymerase, $5 \mu \mathrm{L} 10 \times$ Ex Taq buffer $\left(\mathrm{Mg}^{2+}\right.$ plus), $10 \mathrm{mM}$ dNTPs (all reagents purchased from TaKaRa Biotechnology (Dalian) Co., Ltd, Dalian, China), and 40 pmol primer mix was used per $50 \mu \mathrm{L}$ amplification reaction. The PCR condition is as follows: 5 min initial denaturation at $95^{\circ} \mathrm{C} ; 28$ cycles of denaturation at $95^{\circ} \mathrm{C}(30 \mathrm{~s})$, annealing at $55^{\circ} \mathrm{C}(30 \mathrm{~s})$, elongation at $72{ }^{\circ} \mathrm{C}(45 \mathrm{~s})$, and final extension at $72{ }^{\circ} \mathrm{C}$ for $7 \mathrm{~min}$. The PCR products were purified with magnetic beads (Axygen ${ }^{\circledR}$, NewYork, NY, USA). Amplicon library concentration was estimated with the 2100 Bioanalyzer System (Agilent Technologies ${ }^{\circledR}$, Santa Clara, CA, USA), and equal amount of amplicon from each samples was pooled together. Then the emulsion PCR and sequencing were performed on Ion Torrent Personal Genome Machine (PGM) platform following the manufacturer's recommendations.

Our strategy was a dual-index paired-end sequencing approach. The fusion primers were designed to include the appropriate P5 and P7 Illumina adapter sequences, an eight nucleotide index sequence, and the gene-specific primer. A dual-index sequencing approach allowed us to generate a large number of high-quality sequences while minimizing the cost of long and customized primers [27].

\subsection{Statistical Analyses}

Statistical analyses were performed using SPSS software version 20.0 (IBM, Armonk, NY, USA). Data are expressed as means with their standard deviation. One-way ANOVA was used for multiple comparisons, and results were considered statistically significant if $p$-values were $<0.05$. 


\section{Results}

3.1. Sodium Butyrate Ameliorated Histological Colitis, Which Was Associated with Decreased Proinflammatory Cytokines in IL-10-/- Mice

First, we evaluated the protective effects of sodium butyrate treatment on colitis severity. Compared with wild-type mice, IL-10-/- mice without treatment showed greater infiltration of inflammatory cells in colonic mucosa and higher mean histological scores ( $2.5 \pm 0.58$ vs. $0.25 \pm 0.50$, $p=0.001$ ). However, IL-10 $-/-$ mice receiving sodium butyrate treatment demonstrated a significant reduction in inflammatory cells in the colon, as shown by reduced inflammatory cell infiltration and lower mean inflammatory scores $(1.25 \pm 0.50$ vs. $2.5 \pm 0.58, p=0.025)$. There were no significant differences between the IL-10 $-/$ mice receiving sodium butyrate and wild-type mice (Figure 1).
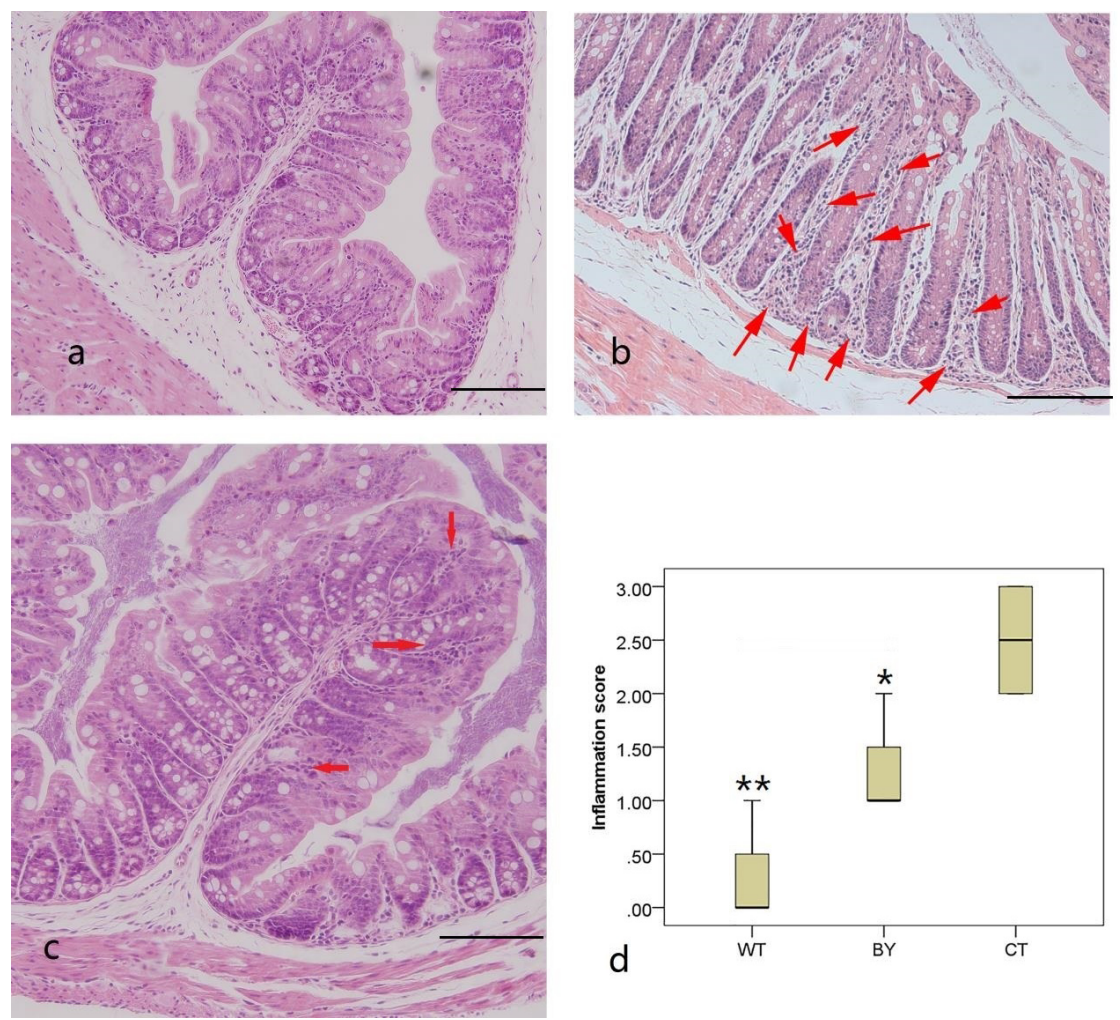

Figure 1. Histological features and scores of the proximal colons from mice in three groups. Representative HE stained sections from three groups $(\times 200$ magnification $)$ are shown. Wild type mice (WT and (a)), IL-10 ${ }^{-/-}$mice without treatment (CT and (b)), interleukin (IL)- $10^{-/-}$mice treated with butyrate (BY and (c)). Arrows indicate infiltration of inflammatory cells. Histological scores of all three groups (d). Data are presented as mean $\pm \operatorname{SEM}\left(n=4\right.$ for each group, Bars $=100 \mu \mathrm{m} .{ }^{*} p<0.05$ and ** $p<0.01$ versus IL-10 $1-$ mice without treatment).

Next, we used qRT-PCR to quantify TNF- $\alpha$ and IL- 6 mRNA of proximal colon in different groups. As shown in Figure 2, the IL-10 ${ }^{-/}-$mice without treatment demonstrated higher expression of IL-6 and TNF- $\alpha$ than controls $(12.92 \pm 1.64$ vs. $8.84 \pm 0.70, p=0.001 ; 11.71 \pm 1.45$ vs. $9.16 \pm 1.48, p=0.014$, respectively). The IL-10 $-/-$ mice receiving sodium butyrate treatment had a significantly lower level of IL-6 and TNF- $\alpha$ than the IL-10 ${ }^{-/-}$mice without treatment $(9.71 \pm 1.15$ vs. $12.92 \pm 1.64, p=0.006$; $8.17 \pm 0.79$ vs. $11.71 \pm 1.45, p=0.002$, respectively), which was comparable to controls $(p=0.388$ and $p=0.285$, respectively). 
a

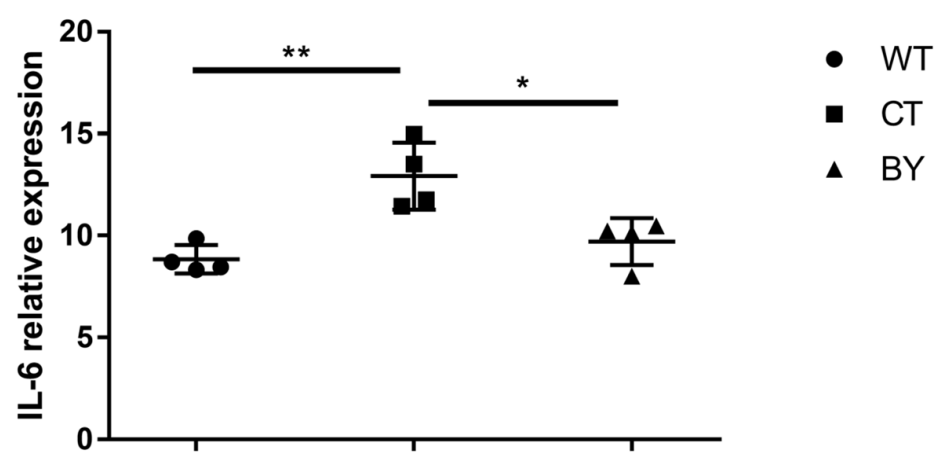

b

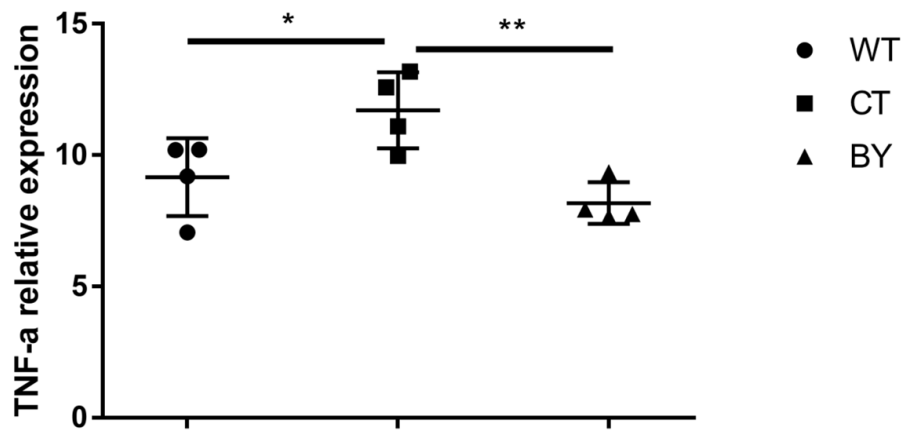

Figure 2. The relative expression of colitis inflammatory factors IL-6 (a) and tumor necrosis factor (TNF)-a (b) of the proximal colons in three groups of mice. Wild-type mice (WT), IL-10-/- mice without treatment (CT), IL-10 $10^{-}$mice treated with butyrate (BY); Data are presented as mean \pm SEM ( $n=4$ for each group, ${ }^{*} p<0.05$ and ${ }^{* *} p<0.01$ versus CT group).

\subsection{The impact of Sodium Butyrate on the Concentrations of SCFAs in Proximal Colon Contents}

Compared with wild-type mice, concentrations of acetate, propionate and sodium butyrate were significantly increased in IL- $10^{-/-}$mice treated with or without sodium butyrate compare to the wild-type mice (acetate: $3.48 \pm 0.27$ vs. $0.76 \pm 0.16 \mu \mathrm{g} / \mathrm{mg}, p<0.001$ and $2.72 \pm 0.42$ vs. $0.76 \pm 0.16 \mu \mathrm{g} / \mathrm{mg}, p<0.001$; propionate: $0.78 \pm 0.18$ vs. $0.25 \pm 0.04 \mu \mathrm{g} / \mathrm{mg}, p=0.001$ and $0.75 \pm 0.17$ vs. $0.25 \pm 0.04 \mu \mathrm{g} / \mathrm{mg}, p=0.001$; sodium butyrate: $1.57 \pm 0.60$ vs. $0.18 \pm 0.06 \mu \mathrm{g} / \mathrm{mg}, p=0.044$ and $1.26 \pm 0.46$ vs. $0.18 \pm 0.06 \mu \mathrm{g} / \mathrm{mg}, p=0.042$, respectively). There were no significant differences in SCFAs concentration between IL-10 ${ }^{-/-}$mice treated without and with sodium butyrate, except for the acetate concentration ( $3.48 \pm 0.27$ vs. $2.72 \pm 0.42 \mu \mathrm{g} / \mathrm{mg}, p=0.006)$ (Figure 3). 


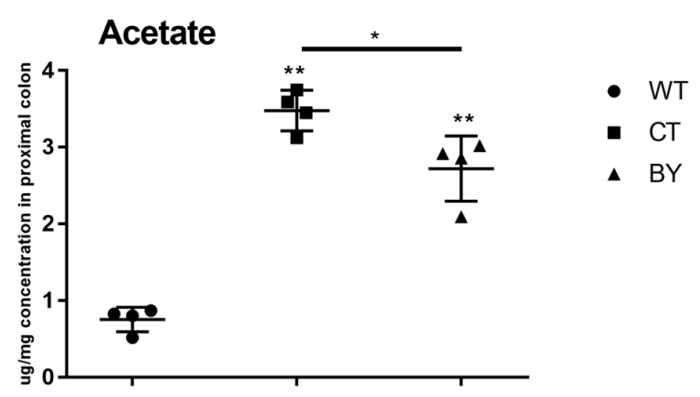

A
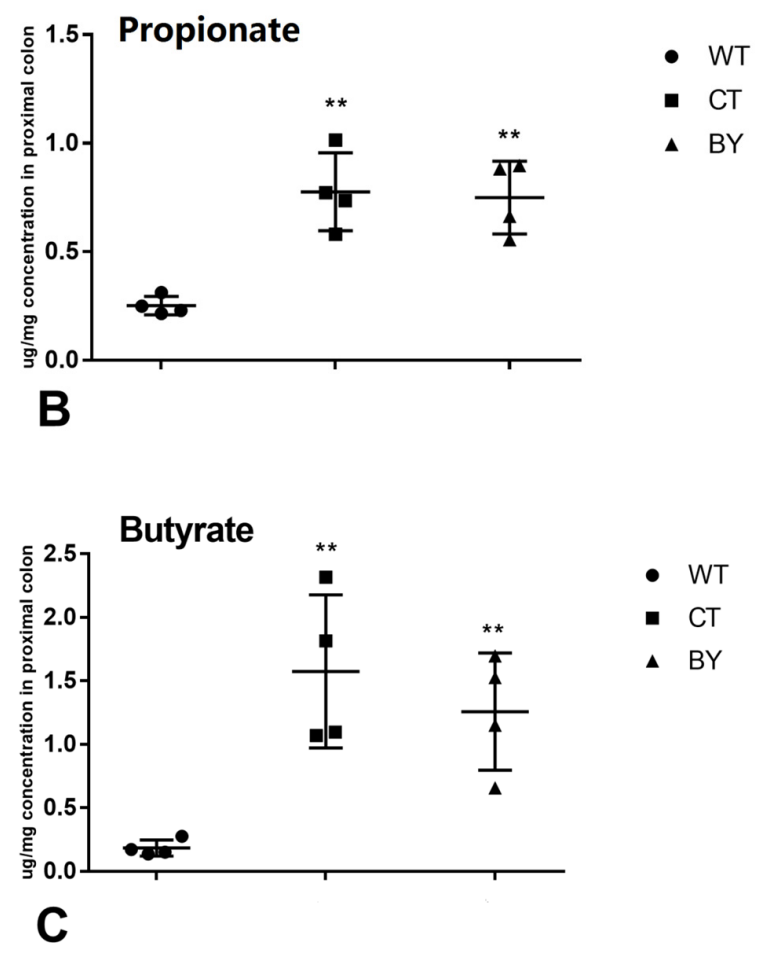

Figure 3. The acetate (A), propionate $(\mathbf{B})$ and butyrate $(\mathbf{C})$ of concentration in proximal colon contents in three groups of mice. Wild-type mice (WT), IL- $10^{-/-}$mice without treatment (CT), IL-10 ${ }^{-/-}$mice treated with butyrate (BY); Data are presented as mean \pm SEM $\left(n=4\right.$ for each group, ${ }^{*} p<0.05$ and ** $p<0.01$ versus WT group).

\subsection{Effects of Sodium Butyrate on the Composition of Microbiota}

Sequencing of $16 \mathrm{~S}$ ribosomal RNA gene tags from stool samples identified the dominant microbiota in all groups to be composed primarily of 2 bacterial phyla, Firmicutes and Bacteroidetes, with minor amounts of Tenericutes and Proteobacteria detected (Figure 4). At the phylum level, compared with IL-10 ${ }^{-/-}$mice without treatment, a reduction in Bacteroidetes $(62.76 \pm 2.38$ vs. $81.07 \% \pm 13.51 \%$, $p=0.046)$ and an increase in Firmicutes ( $32.86 \pm 1.47$ vs. $12.68 \% \pm 10.62 \%, p=0.012)$ in IL-10 $-/-$ mice treated with sodium butyrate was observed. Furthermore, the amount of Firmicutes in IL-10-/mice treated with sodium butyrate was significantly lower than wild-type mice (32.86 \pm 1.47 vs. $47.22 \% \pm 5.69 \%, p=0.046)$ but the amount of Bacteroidetes was not different (62.76 \pm 2.38 vs. $47.73 \pm 7.19, p=0.085)$. 

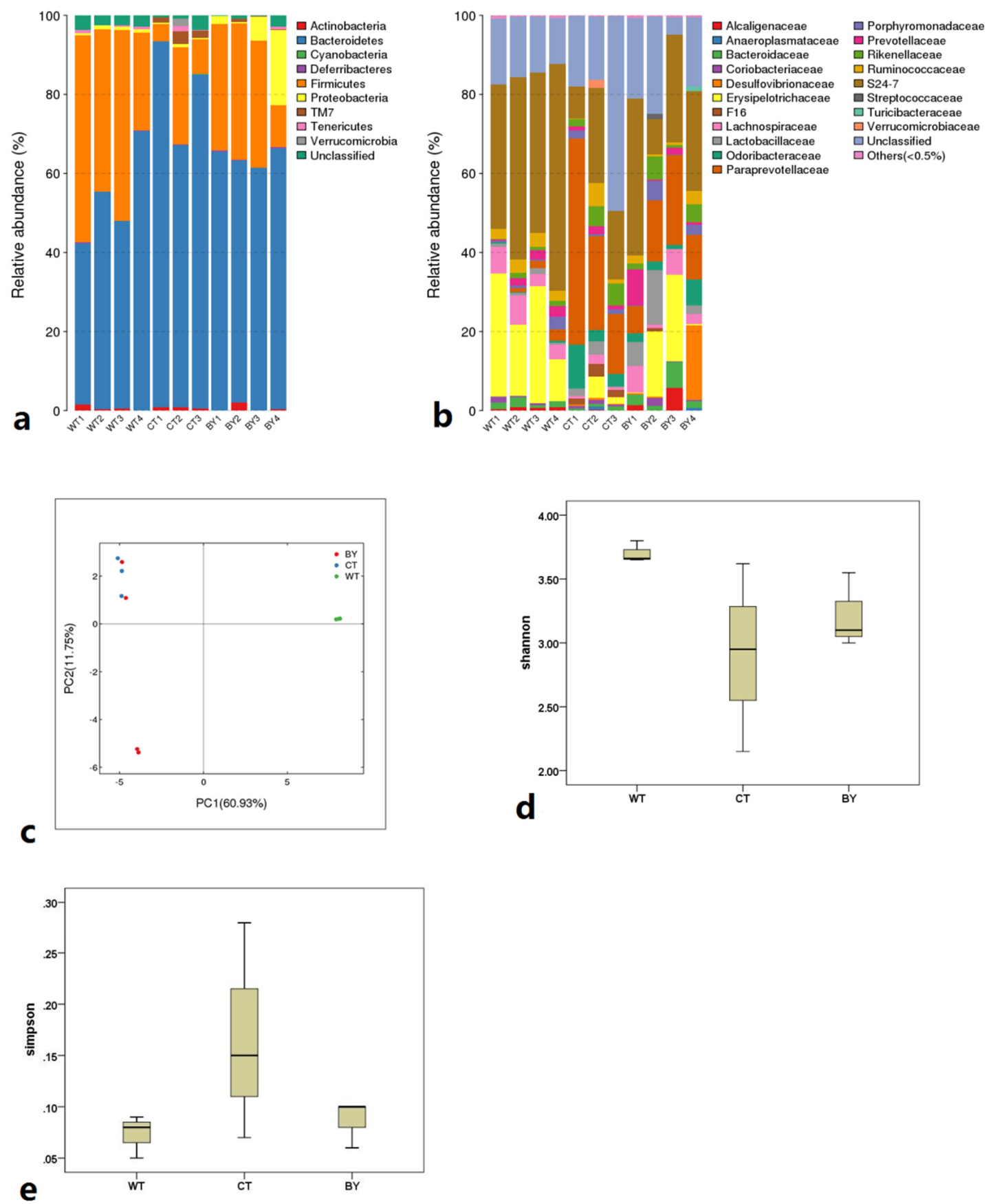

Figure 4. The microbiota composition of proximal colon contents in three groups of mice. The microbiota composition at the phylum level (a) and the family level (b) in three groups, the principal component analysis in three groups (c), the shannon index (d) and the simpson index (e) of biodiversity in three groups, Wild-type mice (WT), IL-10 $-/-$ mice without treatment (CT), IL-10 ${ }^{-/-}$ mice treated with butyrate (BY); Data are presented as mean $\pm \operatorname{SEM}\left({ }^{*} p<0.05\right.$ and ${ }^{* *} p<0.01$ versus CT group).

Additionally, at the family level, Lactobacillaceae and Erysipelotrichaceae were increased in IL-10-/mice treated with sodium butyrate as compared with those without treatment (6.69 \pm 6.75 vs. $1.81 \pm 1.64 \%, p=0.187$ and $12.87 \pm 11.27$ vs. $2.38 \% \pm 2.65 \%, p=0.155)$, although there were no significant differences. At the genus level, the amount of Prevotella in IL-10 $-/$ mice without treatment was significantly higher than wild-type mice (31.68 \pm 19.23 vs. $2.34 \% \pm 1.87 \%, p=0.021)$, but was reduced in IL-10 ${ }^{-/-}$mice treated with sodium butyrate (31.68 \pm 19.23 vs. $\left.18.79 \% \pm 16.18 \%, p=0.219\right)$. 
There were no significant differences between IL-10-/- mice treated with sodium butyrate and wild-type mice $(p=0.131)$. We also found that sodium butyrate-producing Eubacterium bacteria in wild-type mice was significantly higher than other groups $(25.67 \pm 11.24$ vs. $0.00, p=0.003$; $25.67 \pm 11.24$ vs. $0.00, p=0.003$ ). However, sodium butyrate-producing Clostridium bacteria in wild-type mice was lower than IL-10 ${ }^{-/-}$mice without treatment $(0.00$ vs. $46.00 \pm 42.04, p=0.060$; 0.00 vs. $2.33 \pm 2.31, p=0.910$ ). Furthermore, there were no significant differences of Roseburia in groups.

The principal component analysis found that the similarity in both wild-type mice and IL-10 $10^{-/-}$ mice without treatment was high, although one sample in IL-10 ${ }^{-/}$mice treated with sodium butyrate had a low similarity. The diversity analysis showed that the abundance of microbiota in IL-10-/mice treated with sodium butyrate was slightly higher than those without treatment (Shannon index: $3.22 \pm 0.29$ vs. $2.91 \pm 0.74, p=0.441$; Simpson index: $0.09 \pm 0.02$ vs. $0.17 \pm 0.11, p=0.175$ ), but the biodiversity in wild-type mice also tended to be higher than in IL-10 ${ }^{-1-}$ mice treated with sodium butyrate (Shannon index: $3.70 \pm 0.08$ vs. $3.22 \pm 0.29, p=0.243$; Simpson index: $0.07 \pm 0.02$ vs. $0.09 \pm 0.02, p=0.806)$. However, none of these differences were statistically significant.

\subsection{Sodium Butyrate Reduced the Amount of IgA-Coated Bacteria}

IgA-coated bacteria were previously found to have a role in driving IBD and targeted elimination of such bacteria may reduce, reverse, or even prevent disease development [9]. Therefore, we measured the levels of IgA-coated bacteria in mouse feces using flow cytometry (Figure 5). The amount of IgA-coated bacteria was significantly higher in IL-10 $0^{-/}$mice compared with wild-type mice $(80.5 \pm 12.10$ vs. $54.8 \% \pm 2.12 \%, p=0.001)$, however, in sodium butyrate-treated mice, the amount of IgA-coated bacteria was significantly decreased ( $44.7 \pm 0.92$ vs. $80.5 \% \pm 12.10 \%, p<0.001)$, and there was no significant difference between wild-type mice and the IL- $10^{-/-}$mice receiving sodium butyrate treatment $(p=0.087)$.
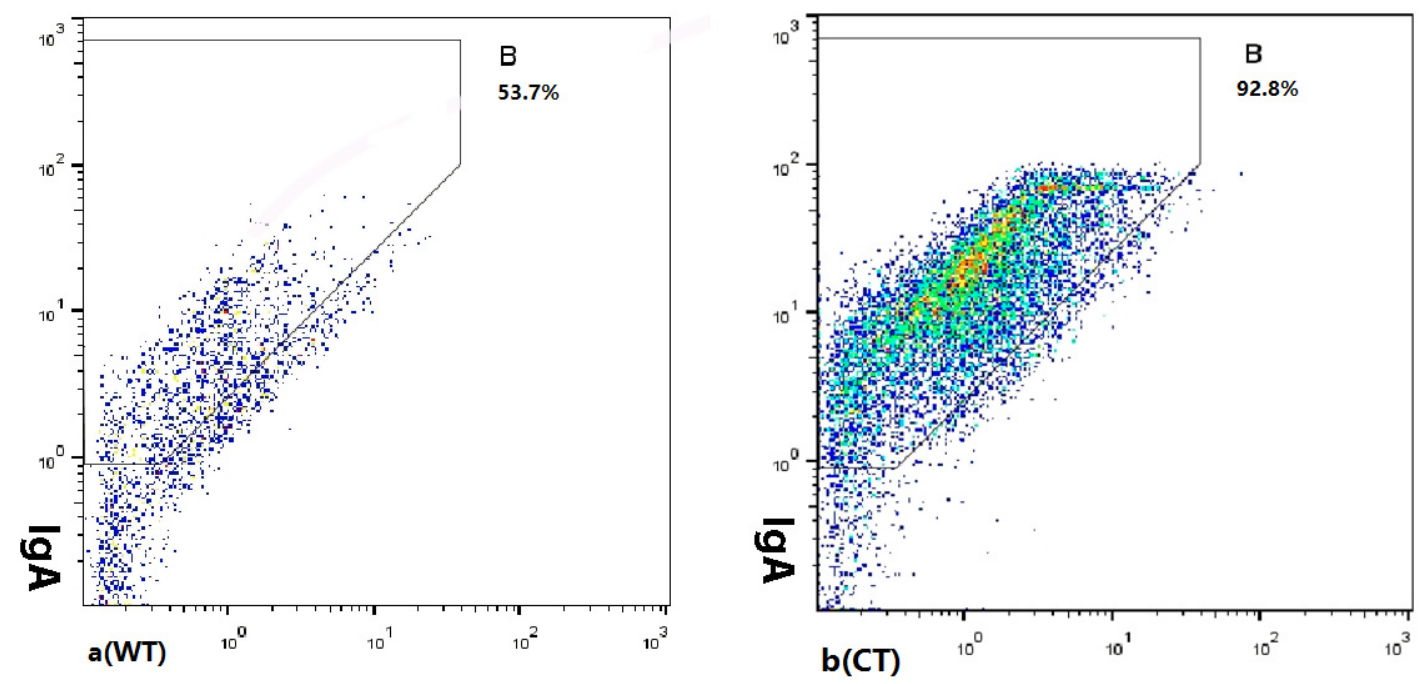

Figure 5. Cont. 

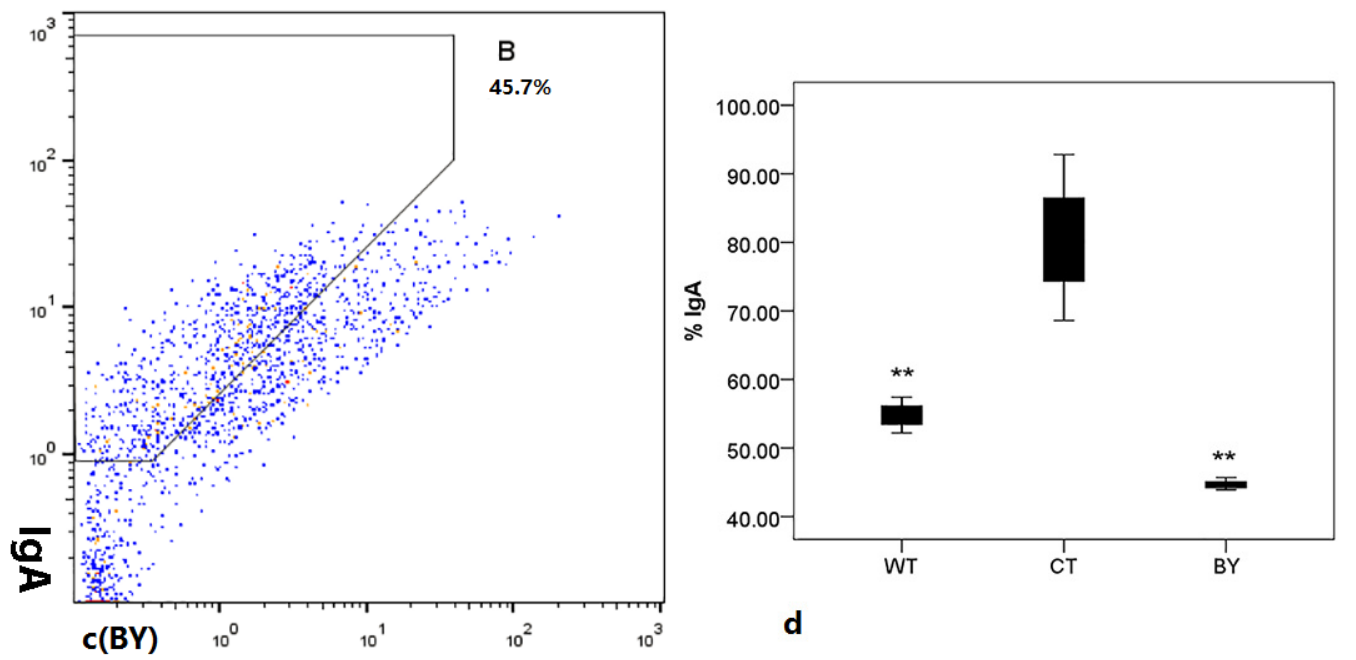

Figure 5. The IgA coating bacteria detected by the Flow Cytometry and the percent of IgA coating bacteria (d) in proximal colon contents in three groups of mice. Wild-type mice ((a), WT), IL-10 ${ }^{-/-}$ mice without treatment ((b), CT), IL-10 $1-$ mice treated with butyrate ((c), BY); Data are presented as mean $\pm \operatorname{SEM}\left(n=4\right.$ for each group, ${ }^{*} p<0.05$ and ${ }^{* *} p<0.01$ versus CT group).

\section{Discussion}

Our study shows that sodium butyrate ameliorated histological colitis which was associated with a reduction in the amount of IgA-coated bacteria, modified the composition of the microbiome and changed the SCFAs concentration in the colon in IL-10 ${ }^{-/}$mice.

Many studies have revealed effects of soluble dietary fiber on inflammation in IBD $[15,16,28]$ but the mechanisms behind such effects remain largely unknown. SCFAs, fermented from soluble fiber by certain species of gut bacteria, have a crucial role as a fuel source for intestinal epithelial cells [17] and exert effects on both gut morphology and function [18]. Previous reports showed a decrease in sodium butyrate after feeding rats a diet containing $5 \%$ pectin $[29,30]$; however, other studies have shown an increase in sodium butyrate concentration after feeding apple pectin to animals included rats, pigs and mice [31-33]. In the current study, significantly higher concentrations of acetate, propionate and

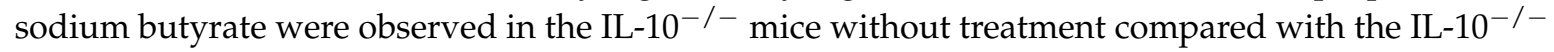
mice receiving sodium butyrate, which is consistent with a report that the concentration of SCFAs in mice with dextran sulfate sodium (DSS)-induced colitis treated with sodium butyrate were lower than those without treatment [30]. These inconsistencies suggest that SCFAs were lost or not totally absorbed in the damaged gut mucosa of IL-10 $10^{-/-}$mice and sodium butyrate increased metabolism or absorption of SCFA in the colon.

Sodium butyrate-producing bacteria, including Clostridium, Eubacterium and Fusobacterium, mainly live in the caecum and colon. A Japanese study found that sodium butyrate-producing bacterial species, such as Blautia faecis, Roseburia inulinivorans, Ruminococcus torques, Clostridium lavalense, Bacteroides uniformis and Faecalibacterium prausnitzii were significantly reduced in CD patients compared with healthy individuals [34]. A reduction in Roseburia hominis and F. prausnitzii, both well-known sodium butyrate-producing bacteria of the Firmicutes phylum, was also observed in ulcerative colitis patients [22]. It was also found that SCFAs were reduced, but no direct correlation between SCFA and the identified bacteria was found. Depletion of sodium butyrate-producing bacteria in IBD microbiota is clearly evidenced by a reduction in sodium butyrate-producing metabolic pathways [19,20], as well as change in concentrations of fecal sodium butyrate [21,22]. We found that levels of sodium butyrate-producing Eubacterium bacteria in wild-type mice were significantly higher than other groups. However, levels of sodium butyrate-producing Clostridium bacteria in IL-10 $10^{-/-}$mice receiving sodium butyrate were higher than wild-type mice. This trend is consistent 
with the concentration of sodium butyrate. Therefore, these results suggest that altering the microbiota (resulting in more butyrate-producing bacteria) would be an alternative long-term treatment option to ongoing supplementation with butyrate. The paradoxical results might be explained by the limited numbers of mice per group or the dysbiosis of the gut microbiota. Therefore, further investigation will be needed to confirm this hypothesis.

Studies suggest that dysbiosis of the gut microbiota, as characterized by decreases in the proportions of Firmicutes and F. prausnitzii and increases in Bacteroidetes and Enterobacteriaceae [4,35,36] is a major characteristic of IBD. The effects of the composition of the intestinal microbiota on disease progress in mouse models of IBD have been examined in studies which found particular bacterial taxa within the intestinal microbiota, such as Prevotellaceae [37,38] and Helicobacter species [39], can drive chronic intestinal inflammation or exacerbate colitis. Furthermore, a study reported that bacteria isolated from patients with IBD and selected based on high IgA-coating induced potent IgA responses and dramatically exacerbated the development of DSS-induced colitis in gnotobiotic mice [9]. In the present study, we found that sodium butyrate reduced the amount of IgA-coated bacteria in IL-10 $10^{-/-}$mice. IgA is prominently secreted at mucosal surfaces and coats a fraction of the intestinal microbiota [40]. IgA can mediate protective immunity to enteric pathogens including viruses, bacteria, and toxins [41]. Moreover, one study found that sodium butyrate regulates the size and function of the colonic Treg pool and protects against colitis in a GPR43-dependent manner in mice [23]. Therefore, sodium butyrate might reduce the amount of IgA-coated bacteria through improving protective immunity to enteric pathogens.

In the current study, dysbiosis of the gut microbiota was regulated by oral administration of sodium butyrate in IL-10 $10^{-/-}$mice, specifically an increase in the proportion of Firmicutes and Lactobacillus and decrease in Bacteroidetes and Prevotella. Furthermore, it also modified the abundance of the gut microbiota. Previous studies found decreased biodiversity of microbiota in IBD patients and mice [5,42-45] and a clinical trial showed that ulcerative colitis patients receiving fecal microbiota transplantation had greater microbial diversity than those given the placebo, and more patients who had greater microbial diversity went into remission [46]. Therefore, we consider modifying dysbiosis and enriching biodiversity might be important mechanisms in sodium butyrate amelioration of colitis in IL-10 $0^{-/-}$mice.

This study has several limitations. First, though the results are in accord with our hypothesis, there were no significant differences in some bacteria when analyzing the composition of microbiota, which might be due to the limited number of mice per group. Second, a similar clinical study performed in patients with IBD needs to be undertaken. Last, a rigorous causal relationship between colitis and the composition of microbiota in this study was not confirmed.

\section{Conclusions}

In summary, our data provide evidence that oral treatment with sodium butyrate protects against colitis, possibly through reducing the amount of colitogenic IgA-coated bacteria and modifying gut microbiota in IL-10 $10^{-/}$mice. An increased understanding of the protective mechanism of sodium butyrate might shed light on potential novel therapeutic options in patients with IBD.

Acknowledgments: The work was supported by National Natural Science Foundation of China (81270006).

Author Contributions: Tenghui Zhang, Chao Ding, Jianfeng Gong, Weiming Zhu, Ning Li, Jieshou Li conceived and designed the experiments. Tenghui Zhang, Chao Ding, Mingli Zhao, Xujie Dai, Jianbo Yang performed the experiment. Tenghui Zhang, Chao Ding Yi Li, Lili Gu, Yao Wei, Jianfeng Gong analyzed the data. Tenghui Zhang, Chao Ding and Jianfeng Gong drafted the manuscript. Jianfeng Gong, Weiming Zhu, Ning Li, and Jieshou Li reviewed the manuscript. All authors read and approved the manuscript.

Conflicts of Interest: The authors declare no conflicts of interest. The founding sponsors had no role in the design of the study, in the collection, analyses, or interpretation of data, in the writing of the manuscript, and in the decision to publish the results. 


\section{References}

1. Elson, C.O.; Cong, Y.; McCracken, V.J.; Dimmitt, R.A.; Lorenz, R.G.; Weaver, C.T. Experimental models of inflammatory bowel disease reveal innate, adaptive, and regulatory mechanisms of host dialogue with the microbiota. Immunol. Rev. 2005, 206, 260-276. [CrossRef] [PubMed]

2. Willing, B.P.; Dicksved, J.; Halfvarson, J.; Andersson, A.F.; Lucio, M.; Zheng, Z.; Engstrand, L. A pyrosequencing study in twins shows that gastrointestinal microbial profiles vary with inflammatory bowel disease phenotypes. Gastroenterology 2010, 139, 1844-1854. [CrossRef] [PubMed]

3. Maharshak, N.; Packey, C.D.; Ellermann, M.; Manick, S.; Siddle, J.P.; Huh, E.Y.; Carroll, I.M. Altered enteric microbiota ecology in interleukin 10-deficient mice during development and progression of intestinal inflammation. Gut Microb. 2013, 4, 316-324. [CrossRef] [PubMed]

4. Kang, S.; Denman, S.E.; Morrison, M.; Yu, Z.; Dore, J.; Leclerc, M.; McSweeney, C.S. Dysbiosis of fecal microbiota in Crohn's disease patients as revealed by a custom phylogenetic microarray. Inflamm. Bowel Dis. 2010, 16, 2034-2042. [CrossRef] [PubMed]

5. Manichanh, C.; Rigottier-Gois, L.; Bonnaud, E.; Gloux, K.; Pelletier, E.; Frangeul, L.; Roca, J. Reduced diversity of faecal microbiota in Crohn's disease revealed by a metagenomic approach. Gut 2006, 55, $205-211$. [CrossRef] [PubMed]

6. Lupp, C.; Robertson, M.L.; Wickham, M.E.; Sekirov, I.; Champion, O.L.; Gaynor, E.C.; Finlay, B.B. Host-mediated inflammation disrupts the intestinal microbiota and promotes the overgrowth of Enterobacteriaceae. Cell Host Microbe 2007, 2, 119-129. [CrossRef] [PubMed]

7. Ambrose, N.S.; Johnson, M.; Burdon, D.W.; Keighley, M.R. Incidence of pathogenic bacteria from mesenteric lymph nodes and ileal serosa during Crohn's disease surgery. Br. J. Surg. 1984, 71, 623-625. [CrossRef] [PubMed]

8. Takesue, Y.; Ohge, H.; Uemura, K.; Imamura, Y.; Murakami, Y.; Yokoyama, T.; Sueda, T. Bacterial translocation in patients with Crohn's disease undergoing surgery. Dis. Colon Rectum 2002, 45, 1665-1671. [CrossRef] [PubMed]

9. Palm, N.W.; De Zoete, M.R.; Cullen, T.W.; Barry, N.A.; Stefanowski, J.; Hao, L.; Ruggiero, E. Immunoglobulin A coating identifies colitogenic bacteria in inflammatory bowel disease. Cell 2014, 158, 1000-1010. [CrossRef] [PubMed]

10. Macpherson, A.J.; Uhr, T. Induction of protective IgA by intestinal dendritic cells carrying commensal bacteria. Science 2004, 303, 1662-1665. [CrossRef] [PubMed]

11. Pabst, O. New concepts in the generation and functions of IgA. Nat. Rev. Immunol. 2012, 12, 821-832. [CrossRef] [PubMed]

12. Ley, R.E.; Hamady, M.; Lozupone, C.; Turnbaugh, P.J.; Ramey, R.R.; Bircher, J.S.; Gordon, J.I. Evolution of mammals and their gut microbes. Science 2008, 320, 1647-1651. [CrossRef] [PubMed]

13. De Filippo, C.; Cavalieri, D.; Di Paola, M.; Ramazzotti, M.; Poullet, J.B.; Massart, S.; Lionetti, P. Impact of diet in shaping gut microbiota revealed by a comparative study in children from Europe and rural Africa. Proc. Nat. Acad. Sci. USA 2010, 107, 14691-14696. [CrossRef] [PubMed]

14. Liu, L.; Li, Y.H.; Niu, Y.B.; Sun, Y.; Guo, Z.J.; Li, Q.; Mei, Q.B. An apple oligogalactan prevents against inflammation and carcinogenesis by targeting LPS/TLR4/NF- $k B$ pathway in a mouse model of colitis-associated colon cancer. Carcinogenesis 2010, 31, 1822-1832. [CrossRef] [PubMed]

15. Ye, M.B.; Lim, B.O. Dietary pectin regulates the levels of inflammatory cytokines and immunoglobulins in interleukin-10 knockout mice. J. Agric. Food Chem. 2010, 58, 11281-11286. [CrossRef] [PubMed]

16. Bassaganya-Riera, J.; DiGuardo, M.; Viladomiu, M.; De Horna, A.; Sanchez, S.; Einerhand, A.W.; Hontecillas, R. Soluble fibers and resistant starch ameliorate disease activity in interleukin-10-deficient mice with inflammatory bowel disease. J. Nutr. 2011, 141, 1318-1325. [CrossRef] [PubMed]

17. Roediger, W.E. Role of anaerobic bacteria in the metabolic welfare of the colonic mucosa in man. Gut 1980, 21, 793-798. [CrossRef] [PubMed]

18. Binder, H.J.; Mehta, P. Short-chain fatty acids stimulate active sodium and chloride absorption in vitro in the rat distal colon. Gastroenterology 1989, 96, 989-996. [CrossRef]

19. Morgan, X.C.; Tickle, T.L.; Sokol, H.; Gevers, D.; Devaney, K.L.; Ward, D.V.; Bousvaros, A. Dysfunction of the intestinal microbiome in inflammatory bowel disease and treatment. Genome Biol. 2012, 13, R79. [CrossRef] [PubMed] 
20. Erickson, A.R.; Cantarel, B.L.; Lamendella, R.; Darzi, Y.; Mongodin, E.F.; Pan, C.; Raes, J. Integrated metagenomics/metaproteomics reveals human host-microbiota signatures of Crohn's disease. PLoS ONE 2012, 7, e49138. [CrossRef] [PubMed]

21. De Preter, V.; Joossens, M.; Ballet, V.; Shkedy, Z.; Rutgeerts, P.; Vermeire, S.; Verbeke, K. Metabolic profiling of the impact of oligofructose-enriched inulin in Crohn's disease patients: A double-blinded randomized controlled trial. Clin. Transl. Gastroenterol. 2013, 4, e30. [CrossRef] [PubMed]

22. Machiels, K.; Joossens, M.; Sabino, J.; De Preter, V.; Arijs, I.; Eeckhaut, V.; Ferrante, M. A decrease of the butyrate-producing species Roseburia hominis and Faecalibacterium prausnitzii defines dysbiosis in patients with ulcerative colitis. Gut 2014, 63, 1275-1283. [CrossRef] [PubMed]

23. Smith, P.M.; Howitt, M.R.; Panikov, N.; Michaud, M.; Gallini, C.A.; Bohlooly, Y.M.; Garrett, W.S. The microbial metabolites, short-chain fatty acids, regulate colonic Treg cell homeostasis. Science 2013, 341, 569-573. [CrossRef] [PubMed]

24. Berg, D.J.; Davidson, N.; Kuhn, R.; Muller, W.; Menon, S.; Holland, G.; Rennick, D. Enterocolitis and colon cancer in interleukin-10-deficient mice are associated with aberrant cytokine production and CD4(+) TH1-like responses. J. Clin. Investig. 1996, 98, 1010-1020. [CrossRef] [PubMed]

25. Zheng, X.; Qiu, Y.; Zhong, W.; Baxter, S.; Su, M.; Li, Q.; Zeisel, S.H. A targeted metabolomic protocol for short-chain fatty acids and branched-chain amino acids. Metabolomics 2013, 9, 818-827. [CrossRef] [PubMed]

26. Geremia, A.; Arancibia-Carcamo, C.V.; Fleming, M.P.; Rust, N.; Singh, B.; Mortensen, N.J.; Powrie, F. IL-23-responsive innate lymphoid cells are increased in inflammatory bowel disease. J. Exp. Med. 2011, 208, 1127-1133. [CrossRef] [PubMed]

27. Fadrosh, D.W.; Ma, B.; Gajer, P.; Sengamalay, N.; Ott, S.; Brotman, R.M.; Ravel, J. An improved dual-indexing approach for multiplexed $16 S$ rRNA gene sequencing on the Illumina MiSeq platform. Microbiome 2014, 2, 6. [CrossRef] [PubMed]

28. Wedlake, L.; Slack, N.; Andreyev, H.J.; Whelan, K. Fiber in the treatment and maintenance of inflammatory bowel disease: A systematic review of randomized controlled trials. Inflamm. Bowel Dis. 2014, 20, 576-586. [CrossRef] [PubMed]

29. Thomsen, L.L.; Roberton, A.M.; Wong, J.; Lee, S.P.; Tasman-Jones, C. Intra-caecal short chain fatty acids are altered by dietary pectin in the rat. Digestion 1984, 29, 129-137. [CrossRef] [PubMed]

30. Vieira, E.L.; Leonel, A.J.; Sad, A.P.; Beltrao, N.R.; Costa, T.F.; Ferreira, T.M.; Alvarez-Leite, J.I. Oral administration of sodium butyrate attenuates inflammation and mucosal lesion in experimental acute ulcerative colitis. J. Nutr. Biochem. 2012, 23, 430-436. [CrossRef] [PubMed]

31. Waldecker, M.; Kautenburger, T.; Daumann, H.; Veeriah, S.; Will, F.; Dietrich, H.; Schrenk, D. Histone-deacetylase inhibition and butyrate formation: Fecal slurry incubations with apple pectin and apple juice extracts. Nutrition 2008, 24, 366-374. [CrossRef] [PubMed]

32. Zacharias, B.; Kerler, A.; Drochner, W. The influence of $5 \%$ and $10 \%$ dietary apple pectin on parameters of fermentation in faeces and caecal digesta of weaning pigs. Arch. Anim. Nutr. 2004, 58, 149-156. [CrossRef] [PubMed]

33. Licht, T.R.; Hansen, M.; Bergstrom, A.; Poulsen, M.; Krath, B.N.; Markowski, J.; Wilcks, A. Effects of apples and specific apple components on the cecal environment of conventional rats: Role of apple pectin. BMC Microbial. 2010, 10, 13. [CrossRef] [PubMed]

34. Takahashi, K.; Nishida, A.; Fujimoto, T.; Fujii, M.; Shioya, M.; Imaeda, H.; Sugimoto, M. Reduced abundance of butyrate-producing bacteria species in the fecal microbial community in Crohn's disease. Digestion 2016, 93, 59-65. [CrossRef] [PubMed]

35. Baumgart, M.; Dogan, B.; Rishniw, M.; Weitzman, G.; Bosworth, B.; Yantiss, R.; Berg, D. Culture independent analysis of ileal mucosa reveals a selective increase in invasive Escherichia coli of novel phylogeny relative to depletion of Clostridiales in Crohn's disease involving the ileum. ISME J. 2007, 1, 403-418. [CrossRef] [PubMed]

36. Walker, A.W.; Sanderson, J.D.; Churcher, C.; Parkes, G.C.; Hudspith, B.N.; Rayment, N.; Petrovska, L. High-throughput clone library analysis of the mucosa-associated microbiota reveals dysbiosis and differences between inflamed and non-inflamed regions of the intestine in inflammatory bowel disease. BMC Microbial. 2011, 11, 7. [CrossRef] [PubMed]

37. Elinav, E.; Strowig, T.; Kau, A.L.; Henao-Mejia, J.; Thaiss, C.A.; Booth, C.J.; Flavell, R.A. NLRP6 inflammasome regulates colonic microbial ecology and risk for colitis. Cell 2011, 145, 745-757. [CrossRef] [PubMed] 
38. Scher, J.U.; Sczesnak, A.; Longman, R.S.; Segata, N.; Ubeda, C.; Bielski, C.; Huttenhower, C. Expansion of intestinal Prevotella copri correlates with enhanced susceptibility to arthritis. Elife 2013, 2, e01202. [CrossRef] [PubMed]

39. Kullberg, M.C.; Ward, J.M.; Gorelick, P.L.; Caspar, P.; Hieny, S.; Cheever, A.; Sher, A. Helicobacter hepaticus triggers colitis in specific-pathogen-free interleukin-10 (IL-10)-deficient mice through an IL-12- and gamma interferon-dependent mechanism. Infect. Immun. 1998, 66, 5157-5166. [PubMed]

40. Slack, E.; Balmer, M.L.; Fritz, J.H.; Hapfelmeier, S. Functional flexibility of intestinal IgA-broadening the fine line. Front. Immunol. 2012, 3, 100. [CrossRef] [PubMed]

41. Van Der Waaij, L.A.; Mesander, G.; Limburg, P.C.; Van der Waaij, D. Direct flow cytometry of anaerobic bacteria in human feces. Cytometry 1994, 16, 270-279. [CrossRef] [PubMed]

42. Alipour, M.; Zaidi, D.; Valcheva, R.; Jovel, J.; Martinez, I.; Sergi, C.; Carroll, M.W. Mucosal barrier depletion and loss of bacterial diversity are primary abnormalities in paediatric ulcerative colitis. J. Crohn's Colitis 2016, 10, 462-471. [CrossRef] [PubMed]

43. Andoh, A.; Kuzuoka, H.; Tsujikawa, T.; Nakamura, S.; Hirai, F.; Suzuki, Y.; Matsumoto, T. Multicenter analysis of fecal microbiota profiles in Japanese patients with Crohn's disease. J. Gastroenterol. 2012, 47, 1298-1307. [CrossRef] [PubMed]

44. Maukonen, J.; Kolho, K.L.; Paasela, M.; Honkanen, J.; Klemetti, P.; Vaarala, O.; Saarela, M. Altered fecal microbiota in paediatric inflammatory bowel disease. J. Crohn's Colitis 2015, 9, 1088-1095. [CrossRef] [PubMed]

45. Bassett, S.A.; Young, W.; Barnett, M.P.; Cookson, A.L.; McNabb, W.C.; Roy, N.C. Changes in composition of caecal microbiota associated with increased colon inflammation in interleukin-10 gene-deficient mice inoculated with Enterococcus species. Nutrients 2015, 7, 1798-1816. [CrossRef] [PubMed]

46. Moayyedi, P.; Surette, M.G.; Kim, P.T.; Libertucci, J.; Wolfe, M.; Onischi, C.; Lee, C.H. Fecal microbiota transplantation induces remission in patients with active ulcerative colitis in a randomized controlled trial. Gastroenterology 2015, 149, 102-109. [CrossRef] [PubMed]

(C) 2016 by the authors; licensee MDPI, Basel, Switzerland. This article is an open access article distributed under the terms and conditions of the Creative Commons Attribution (CC-BY) license (http:/ / creativecommons.org/licenses/by/4.0/). 